\title{
Biogenesis of mitochondrial proteins
}

\author{
Regulation of production of $\delta$-aminolaevulinate synthase by haemin in embryonic-chick liver
}

\author{
Ibrahim Z. ADES, Keith G. HARPE* and Theresa M. STEVENS \\ Laboratories of Cell Biology, Department of Zoology, University of Maryland, College Park, \\ MD 20742, U.S.A.
}

(Received 11 April 1983/Accepted 14 June 1983)

\begin{abstract}
The effect of haemin on the biogenesis of $\delta$-aminolaevulinate synthase (ALA synthase) was investigated in primary cultures of embryonic-chick liver. The activity of the enzyme and the amount of the enzyme detected by 'immune-blotting' were determined in hepatocytes incubated with the porphyrogenic agent allylisopropylacetamide. The results of these studies indicated that the loss in ALA synthase activity in cells incubated in the presence of haemin $(10 \mu \mathrm{M})$ was roughly proportional to a loss in the immune-reactive mass of the enzyme. Haemin was as effective as cycloheximide in causing depletion of ALA synthase in hepatocytes. We had previously established that haemin blocked the maturation of the precursor of ALA synthase [Ades (1983) Biochem. Biophys. Res. Commun. 110, 42-47]. From results reported in the present paper on analyses of immune-precipitated ALA synthase after pulse-labelling with $\left.{ }^{[35} \mathrm{S}\right]$ methionine in the presence and in the absence of haemin, we determined that the inhibition of processing of pre-ALA synthase in cells by haemin was concentration-dependent. A concentration of $2 \mu \mathrm{M}$ in the culture medium blocked the processing of pre-ALA synthase by $50 \%$ in hepatocytes. We also determined that, after inhibition of its maturation by haemin, pre-ALA synthase turned-over with a half-time of $30 \mathrm{~min}$; on the other hand, mature ALA synthase turned-over with a half-time of $120 \mathrm{~min}$.
\end{abstract}

ALA synthase catalyses the condensation of glycine with succinyl-CoA, to form ALA. In liver, this reaction is the rate-limiting step of the pathway of haem synthesis (Granick \& Sassa, 1971). The enzyme is located in the mitochondrial matrix (Patton \& Beattie, 1973; Scotto et al., 1983), but it is synthesized on cytoplasmic polyribosomes (Sassa \& Granick, 1970; Strand et al., 1972). In our laboratory, we have been studying the enzyme of embryonic-chick liver, a model that has proved to be quite useful for dissecting the mechanisms regulating the expression of ALA synthase. We have established that embryonic-chick liver ALA synthase has a mol.wt. of 63000-65000 (Ades \& Harpe, 1981, 1982) and that the enzyme is synthesized as a

Abbreviations used: ALA synthase, $\delta$-aminolaevulinate synthase (EC 2.3.1.37); AIA, allylisopropylacetamide; BSA, bovine serum albumin; DDC, diethyl 1,4 - dihydro- 2,4,6 - trimethylpyridine - 3,5 - dicarboxylate; PMSF, phenylmethanesulphonyl fluoride; SDS, sodium dodecyl sulphate.

* Present address: East Carolina University School of Medicine, Greenville, NC 27834, U.S.A. precursor with a mol.wt. of 75000 (Ades \& Harpe, 1981). Similar results have been subsequently reported by other investigators for the enzymes of embryonic-chick liver (Borthwick et al., 1983; Srivastava et al., 1983) and of rat liver (Yamamoto et al., 1982; Srivastava et al., 1982).

The activity of ALA synthase in hepatocytes appears to be regulated by the size of the free-haem pool (Welch \& Badawy, 1980; Yamamoto et al., 1981). Studies on animals exposed to porphyrogenic agents to induce liver ALA synthase indicated that haemin blocked the increase in the enzyme's activity (Granick \& Sassa, 1971; Kikuchi \& Hayashi, 1981). Recently we reported that haemin blocked the processing of pre-ALA synthase in primary cultures of hepatocytes exposed to the porphyrogenic agent AIA (Ades, 1983). This finding established a novel mechanism of end-product regulation of maturation of a mitochondrial enzyme. We now report that the decrease in ALA synthase activity in cells treated with haemin could be accounted for by a decrease in the amount of immune-reactive enzyme detected in hepatocytes. 
We also report that the extent of processing of pre-ALA synthase in primary cultures of hepatocytes could be manipulated by the concentration of haemin in the culture medium; after inhibition of its processing by haemin, pre-ALA synthase turnedover.

\section{Experimental}

\section{Preparation of hepatocyte cultures}

Primary cultures of hepatocytes from 17-day-old chick embryos (White Leghorn) were prepared as described previously (Ades, 1983). Basically, livers were perfused with Earle's medium free of $\mathbf{M g}^{2+}$ and $\mathrm{Ca}^{2+}$, then removed from the embryos. Twelve livers were pooled, and the hepatocytes were separated by treatment with collagenase and hyaluronidase. The separated hepatocytes were collected by centrifugation and washed twice with ammonium-containing buffer to lyse red blood cells. The cells were finally suspended in $200 \mathrm{ml}$ of modified Ham's F-12 medium (described below) containing 10\% foetalcalf serum, and portions from the cell suspension were delivered into plastic tissue culture dishes. The cells were maintained at $37^{\circ} \mathrm{C}$ in a humidified incubator (air/ $\left./ \mathrm{CO}_{2}, 19: 1\right)$. After $16 \mathrm{~h}$, the medium was replaced with modified Ham's F-12 medium containing $0.2 \mathrm{mg}$ of insulin $/ \mathrm{ml}$ and $0.5 \mathrm{mg}$ of deferoxamine mesylate/ml (CIBA Pharmaceutical Co., Summit, NJ, U.S.A.). The cells were incubated for $2 \mathrm{~h}$ at $37^{\circ} \mathrm{C}$ and then the medium was replaced with fresh modified Ham's F-12/insulin/deferoxamine medium. AIA was added to the culture medium at this point to a final concentration of $0.075 \mathrm{mg} / \mathrm{ml}$ (from a stock solution of $60 \mathrm{mg}$ of AIA $/ \mathrm{ml}$ of ethanol). AIA was kindly provided by Hoffman-La Roche Inc., Nutley, NJ, U.S.A. Modified Ham's medium was Ham's F-12 medium (Ham, 1965) lacking sodium pyruvate and fatty acids and containing twice the concentration of glutamine; the medium contained (per litre) $10^{5}$ units of penicillin G, $100 \mathrm{mg}$ of streptomycin, $2 \times 10^{4}$ units of nystatin and $10 \mathrm{ml}$ of Fungizone (Flow Laboratories, McLean, VA, U.S.A.).

\section{$A L A$ synthase activity determination}

ALA synthase activity in hepatocyte cultures was determined by the method of Sassa et al. (1979) under the conditions previously described (Ades, 1983). Protein was determined by the method of Lowry et al. (1951) with BSA as standard.

\section{Electrophoretic analyses}

Electrophoretic analyses of proteins were carried out on $1.5 \mathrm{~mm}$-thick slabs of $10 \%$ polyacrylamide gels in the presence of SDS using the system of Laemmli (1970). Proteins labelled with ${ }^{35} \mathrm{~S}$ were detected by fluorography (Bonner \& Laskey, 1974) using Kodak SB-5 X-ray film (Eastman Kodak Company, Rochester, NY, U.S.A.). The standards used in these analyses and their respective molecular weights were: phosphorylase $b, 94000$; BSA, 68000; ovalbumin, 46000; carbonic anhydrase, 30000; and cytochrome $c, 12400$.

\section{Preparation of anti-(ALA synthase)}

Antibodies against purified ALA synthase were prepared by injecting the purified enzyme into New Zealand White rabbits as described previously (Ades \& Harpe, 1981). Serum 160, discussed in the text, was prepared by this procedure. As shown previously (Ades \& Harpe, 1981) and documented further in the Results section, this antiserum crossreacted with ALA synthase as well as a number of other proteins.

More specific antibodies were prepared against ALA synthase purified one step further by separation on denaturing polyacrylamide gels. Serum 472 described elsewhere in the text was prepared by this method. In this procedure, highly purified ALA synthase was first prepared (Ades \& Harpe, 1982), then the constituents of the enzyme preparation were separated by gel electrophoresis in the presence of SDS. Gel slices containing the 52000-Da smear were used for the immunization (Fig. 1). After electrophoresis, a narrow strip of the slab gel was stained to localize the region of the slab containing the band of interest. The stained strip was re-aligned with the rest of the original slab, and the portion of the slab gel containing the 52000-Da band (not stained or fixed) was sliced and saved. To immunize an animal, slices of the gel containing $15-20 \mu \mathrm{g}$ of protein were minced and pulverized in $1.5 \mathrm{ml}$ of $0.9 \% \mathrm{NaCl}$. The suspension was mixed with $1.0 \mathrm{ml}$ of Freund's incomplete adjuvant and $0.5 \mathrm{ml}$ of complete adjuvant. The mixture was emulsified and injected subcutaneously in five or six spots on the back of the White rabbit. At 6-8 weeks after the injection, booster injections were administered to the animal. The injections consisted of gel fragments prepared as described above, but only with Freund's incomplete adjuvant. At 6 weeks after the booster injections, the animal was given a booster consisting of $10 \mu \mathrm{g}$ of the $52000-\mathrm{Da}$ smear of ALA synthase that had been isolated from gel fragments by electrophoretic elution; the protein, in $0.5 \mathrm{ml}$ of $0.9 \% \mathrm{NaCl}$, was emulsified with $0.5 \mathrm{ml}$ of Freund's incomplete adjuvant before intradermal administration to the animal. The animal was bled 8 days after the injection, and whole serum was isolated from the blood and stored at $-20^{\circ} \mathrm{C}$.

\section{Immune precipitation of ALA synthase}

ALA synthase was immune-precipitated from primary cultures of hepatocytes using double- 
antibody precipitation. Primary cultures of hepatocytes labelled with $\left.{ }^{[35} \mathrm{S}\right]$ methionine were rinsed in $0.9 \% \mathrm{NaCl}$ and then scraped in $0.9 \%$ $\mathrm{NaCl}$. The cells were collected by centrifugation and then resuspended in $0.45 \mathrm{ml}$ of $50 \mathrm{~mm}$ - Tris $/ \mathrm{HCl}$, $\mathrm{pH} 7.4$, at $4^{\circ} \mathrm{C}$. The cells were disrupted by mild sonication and brought to $5 \mathrm{~mm}$-PMSF. To this suspension, $0.5 \mathrm{ml}$ of 2-fold-concentrated buffer A (consisting of $1 \mathrm{M}-\mathrm{NaCl}, 20 \mathrm{mM}-\mathrm{Tris} / \mathrm{HCl}, \mathrm{pH} 8.3$, and $2 \%$ Triton $\mathrm{X}-100$ ) was added, and the resulting solution was re-adjusted to $5 \mathrm{mM}$-PMSF. The cell lysate was centrifuged at $15000 \mathrm{~g}$ for $10 \mathrm{~min}$ at $4^{\circ} \mathrm{C}$, and the supernatant was used in the analysis. To immune-precipitate ALA synthase, a portion of the cell lysate was mixed with $3 \mu \mathrm{l}$ of immune-serum and then incubated at $4^{\circ} \mathrm{C}$ for $3 \mathrm{~h}$. At the end of incubation, $0.350 \mathrm{ml}$ of buffer A containing $2.5 \mathrm{mg}$ of goat anti-(rabbit immunoglobulin G) covalently linked to a solid phase (immunobeads obtained from Bio-Rad Laboratories, Richmond, CA, U.S.A.) was added to the lysate, and the suspension was incubated at $4^{\circ} \mathrm{C}$ for $2 \mathrm{~h}$. The immunobeads were then collected by centrifugation and washed twice with $0.8 \mathrm{ml}$ of buffer $A$ followed by two washes with $0.8 \mathrm{ml}$ of $10 \mathrm{~mm}$-Tris $/ \mathrm{HCl}, \mathrm{pH} 8.3$. Immunoprecipitated material was released from the immunobeads by boiling for $3 \mathrm{~min}$ in $0.1 \mathrm{ml}$ of buffer consisting of $5 \%$ SDS, $1 \mathrm{~mm}$-EDTA, $0.1 \mathrm{M}$-Tris $/ \mathrm{HCl}$, pH 6.8, 0.03\% Bromophenol Blue, 20\% glycerol and $1 \% \beta$-mercaptoethanol. The immunobeads were removed by centrifugation, and the immuneprecipitated material was analysed by polyacrylamide-gel electrophoresis.

\section{'Immune-blotting' analyses}

After electrophoresis in the presence of SDS, proteins separated on a polyacrylamide gel were transferred on to a nitrocellulose membrane (BioRad laboratories) using a Bio-Rad Trans-Blot electrophoresis cell. The proteins were transferred electrophoretically at $220 \mathrm{~mA}$ for $3.5 \mathrm{~h}$ in a buffer consisting of $25 \mathrm{~mm}$-Tris, $192 \mathrm{mM}$-glycine and $20 \%$ methanol, pH 8.3. After protein transfer, the nitrocellulose membrane was incubated for $16 \mathrm{~h}$ at room temperature in Tris/saline/Triton buffer $(10 \mathrm{~mm}$ Tris/ $\mathrm{HCl}, \mathrm{pH} 7.4,0.9 \% \mathrm{NaCl}, 1 \%$ Triton $\mathrm{X}-100$ ) containing $5 \mathrm{mg}$ of $\mathrm{BSA} / \mathrm{ml}$. The membrane was rinsed for $15 \mathrm{~min}$ in Tris/saline/Triton and then incubated for $2 \mathrm{~h}$ at room temperature in the same buffer containing $2 \%(\mathrm{v} / \mathrm{v})$ anti-(ALA synthase) serum and $1 \mathrm{mg}$ of $\mathrm{BSA} / \mathrm{ml}$. The membrane was rinsed for $16 \mathrm{~h}$ in Tris/saline/Triton using several changes of the buffer and then incubated at room temperature in the same buffer containing $1 \mathrm{mg}$ of BSA $/ \mathrm{ml}$ and ${ }^{125} \mathrm{I}$-labelled protein A $\left(5 \times 10^{5}\right.$ c.p.m./ $\mathrm{ml}$ of buffer at a specific radioactivity of $6 \times$ $10^{8}$ c.p.m./mg of protein A). After incubation, the membrane was rinsed several times at room tem- perature over a $5 \mathrm{~h}$ period in Tris/saline/Triton then wrapped in thin plastic film (Saran Wrap). Radioiodinated proteins were detected by fluorography with DuPont Cronex X-ray film (E. I. DuPont de Nemours and Co., Wilmington, DE, U.S.A.) and an intensifying screen (DuPont Cronex Lightning-Plus AE).

Protein A was radio-iodinated in our laboratory using the lactoperoxidase and glucose oxidase procedure described previously (Ades \& Harpe, 1982).

\section{Sources of materials}

$\left.{ }^{[35} \mathrm{S}\right]$ Methionine was purchased from Amersham, Arlington Heights, IL, U.S.A. $\mathrm{Na}^{125} \mathrm{I}$ was purchased from New England Nuclear, Boston, MA, U.S.A.

\section{Results}

\section{Preparation of antiserum to ALA synthase}

In previous work, we established that ALA synthase of embryonic-chick liver has a mol.wt. of $63000-65000$ and that the enzyme is highly susceptible to degradation during its purification (Ades \& Harpe, 1981, 1982). Thus after purification, ALA synthase could be recovered mainly as a collection of fragments averaging $52000 \mathrm{Da}$. In order to raise specific antibodies to the enzyme, ALA synthase was purified from chick embryos (Ades \& Harpe, 1982), and then the enzyme preparation was subjected to polyacrylamide-gel electrophoresis in the presence of SDS. Gel slices containing the 52000-Da fragment (Fig. 1) were injected into rabbits to raise the antiserum. The prepared antiserum (472) was analysed by immune-blotting and was found to react with ALA synthase primarily. As seen in Fig. 2, only a single component, with a molecular weight corresponding to that of mature ALA synthase, was detected in liver mitochondria from porphyric chick embryos (antiserum 472, slot b) containing approx. 250-fold the amount of ALA synthase found in liver mitochondria from normal embryos (antiserum 472, slot a) (Ades \& Harpe, 1981). Serum 160 which had been used in our previous studies (Ades \& Harpe, 1981) cross-reacted with one other protein (mol.wt. 44000 ) in liver mitochondria, in addition to crossreacting with ALA synthase in mitochondria from porphyric embryos (Fig. 2, slots $a$ and $b$ ). These results confirmed our previous findings (Ades \& Harpe, 1981) and demonstrated the high specificity of serum $\mathbf{4 7 2}$ for ALA synthase.

\section{Effect of haemin on the amount of ALA synthase in hepatocytes}

It has been suggested that hepatic ALA synthase activity may be inhibited directly by intracellular 


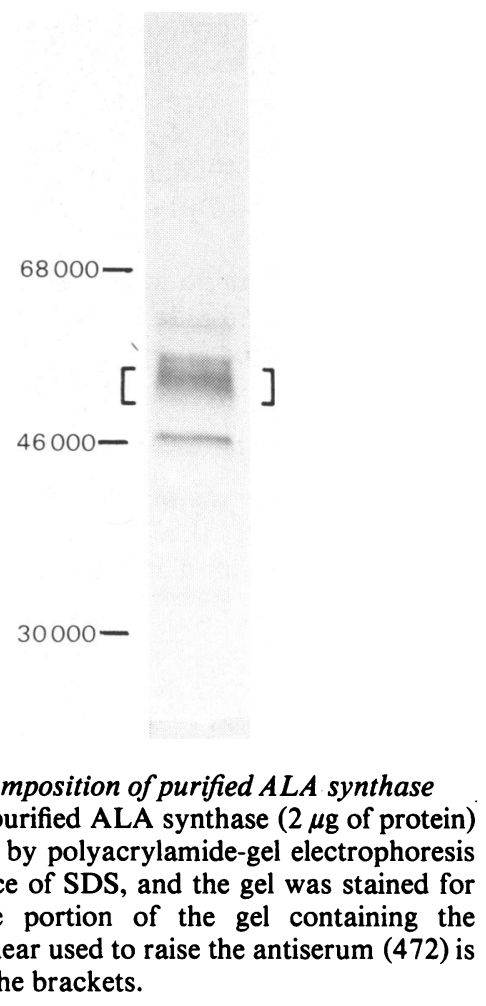

Fig. 1. Composition of purified ALA synthase - A sample of purified ALA synthase ( $2 \mu \mathrm{g}$ of protein) was analysed by polyacrylamide-gel electrophoresis in the presence of SDS, and the gel was stained for proteins. The portion of the gel containing the $52000-\mathrm{Da}$ smear used to raise the antiserum (472) is indicated by the brackets.

haemin, based on observations made with the purified rat liver enzyme (Paterniti \& Beattie, 1979). We examined this possibility by determining the effect of haemin on the activity of ALA synthase and on the amount of the enzyme detected in hepatocytes by immune-blotting analyses. Primary cultures of hepatocytes were incubated with AIA for $14.5 \mathrm{~h}$ and then incubated for $90 \mathrm{~min}$ with haemin, with cycloheximide or with actinomycin $D$ in the presence of AIA. The cells were then harvested and analysed for ALA synthase activity and for their contents of ALA synthase by immune-blotting. In preliminary studies, we had established that the concentrations of cycloheximide and of actinomycin $\mathrm{D}$ used in these studies inhibited the incorporations of $\left[{ }^{3} \mathrm{H}\right]$ leucine and of $\left[{ }^{3} \mathrm{H}\right]$ uridine respectively by better than $95 \%$ in the primary cultures of the hepatocytes. The results in Fig. 3 indicated that cells maintained for $90 \mathrm{~min}$ in the presence of haemin had $50 \%$ of the amount of ALA synthase detected immunochemically as well as $50 \%$ of the ALA synthase activity measured in hepatocytes not exposed to haemin. Thus the lower ALA synthase activity in cells treated with haemin could be fully accounted for by a lower amount of the enzyme in hepatocytes; this was seen consistently in our studies. After a $90 \mathrm{~min}$ incubation of hepato-

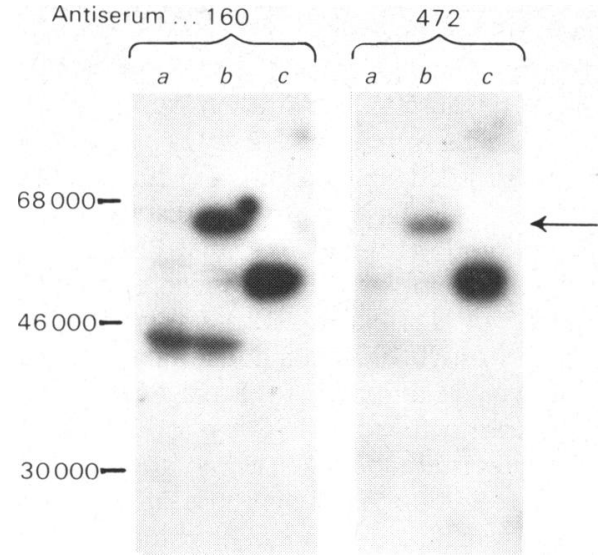

Fig. 2. Determinations of the specificities of the immune sera using immune-blotting analysis

Mitochondria were prepared as described previously (Ades \& Harpe, 1982) from four pooled livers of 18-day-old embryos. The livers had been isolated either from normal embryos or from embryos pre-treated each with $4 \mathrm{mg}$ of DDC plus $2 \mathrm{mg}$ of AIA for $18 \mathrm{~h}$ to increase the mitochondrial content of ALA synthase (Ades \& Harpe, 1981). The mitochondria were solubilized immediately in a boiling buffer consisting of $10 \%$ SDS, 2 mM-EDTA, $1 \% \beta$-mercaptoethanol, $10 \%$ glycerol, $0.05 \mathrm{M}$-Tris/ $\mathrm{HCl}, \mathrm{pH} 6.8$, to a protein concentration of $4 \mathrm{mg} / \mathrm{ml}$. A portion of the resulting solution was then used for polyacrylamide-gel electrophoresis and immuneblotting analyses as described in the Experimental section. Two antisera were tested (160 and 472) in these analyses. A photograph of the slots of interest on the X-ray film is shown in the Figure. The samples analysed were: slot $a, 20 \mu \mathrm{g}$ of mitochondrial protein from normal embryos; $b, 20 \mu \mathrm{g}$ of mitochondrial protein from embryos treated with AIA + DDC; $c$, a portion of the 52000-Da smear purified by electrophoretic elution from the preparation of ALA synthase. The positions of the molecular-weight standards on the original polyacrylamide gel are indicated on the Figure. The arrow indicates the position of ALA synthase.

cytes with cycloheximide, the amount and activity of ALA synthase detected in the cells were similar to the values measured in the cells after incubation with haemin. After incubation with actinomycin D, the amount and activity of ALA synthase detected in cells were intermediate between those measured in cells treated with haemin or cycloheximide and those in cells not exposed to either agent. Haemin thus appeared to be as effective as cycloheximide and more effective than actinomycin $D$ in causing the depletion of the enzyme in hepatocytes. We have previously documented the effectiveness of haemin in suppressing the rise of ALA synthase activity in 


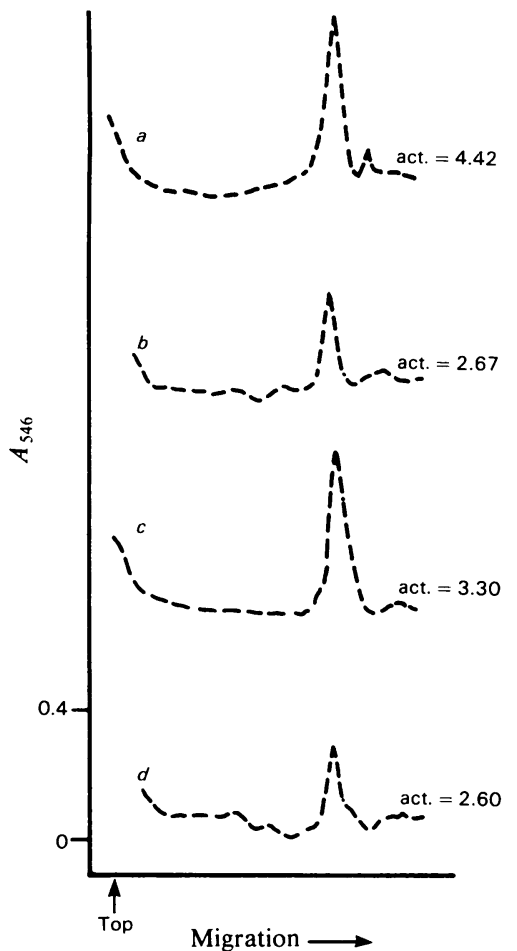

Fig. 3. Effects of haemin, cycloheximide and actinomycin $D$ on the activity and amount of $A L A$ synthase in hepatocytes

Primary cultures of hepatocytes were prepared from chick embryos. The cells were incubated with AIA for $14.5 \mathrm{~h}$ and then the indicated agent was added to the culture medium. The cells were incubated for an additional $90 \mathrm{~min}$ and harvested. For each condition, cells from six $10 \mathrm{~cm}$ culture dishes $(5 \mathrm{mg}$ of protein/ dish) were pooled. Samples from the pooled cells were assayed for ALA synthase activity and for the relative mass of ALA synthase by immune-blotting. For the immune-blotting, a portion containing $30 \mu \mathrm{g}$ of protein for each cell homogenate was used in the electrophoresis. After exposure and development of the X-ray film, the slots on the autoradiogram were scanned with a densitometer. The portions of the scans containing ALA synthase are shown in the Figure. The activities (act.) of ALA synthase determined in the cultures at the various conditions are indicated (in $\mathrm{nmol}$ of ALA produced/h per $\mathrm{mg}$ of protein). The conditions were: $a$, no addition (only AIA being present); $b$, haemin present at $10 \mu \mathrm{M} ; c$, actinomycin D present at $15 \mu \mathrm{g} / \mathrm{ml} ; d$, cycloheximide present at $150 \mu \mathrm{g} / \mathrm{ml}$.

cells in cultures exposed to AIA (Ades, 1983); the equal effectiveness of haemin with that of cycloheximide and its greater effectiveness than that of actinomycin $\mathrm{D}$ in this process has been well documented (Sassa \& Granick, 1979; Strand et al., 1972; Tyrrell \& Marks, 1972) and was consistently observed in our preliminary studies. From the results with cycloheximide (Fig. 3), it was estimated that ALA synthase turned-over with a half time of $110 \mathrm{~min}$ in the primary cultures. This turnover rate was quite close to the rate of loss in ALA synthase activity in cells maintained in the presence of haemin (Ades, 1983). Although haemin was found to block the maturation of ALA synthase (Ades, 1983), there was no indication from these studies that sufficient pre-ALA synthase accumulated in the haemintreated cells to be detectable by the immune-blotting analyses. The precursor in haemin-treated cells could only be detected after pulse-labelling (see below).

\section{Effects of haemin concentration on the biogenesis of ALA synthase}

The effects of various concentrations of haemin on the biogenesis of ALA synthase were investigated in primary cultures of hepatocytes. Cells were incubated with AIA for $5.5 \mathrm{~h}$ and then incubated with $\mathrm{AIA} \pm$ haemin for $45 \mathrm{~min}$ in the presence of $\left[{ }^{35} \mathrm{~S}\right]$ methionine. As seen in Fig. 4, the effect of haemin on the processing of pre-ALA synthase was concentration-dependent. From densitometer scans of the autoradiogram, it was determined that $2.2 \mu \mathrm{M}$-haemin in the culture medium caused a $50 \%$ inhibition in the processing of pre-ALA synthase (Fig. 5). It was also noted from the results in Fig. 4 as well as those from a previous report (Ades, 1983) that haemin significantly inhibited the overall rate of production of pre-ALA synthase. This inhibition could not be accounted for as a result of a haemin-induced block in the synthesis of the enzyme's mRNA; actinomycin D was significantly less effective than $15 \mu \mathrm{M}$-haemin in inhibiting ALA synthase production (Fig. 4). Similar results had been obtained in separate experiments, carried out similarly but using a labelling period of $60 \mathrm{~min}$ and antiserum 160 for the immunoprecipitations; under those conditions, $1.9 \mu \mathrm{M}$-haemin in the culture medium caused a $50 \%$ inhibition in the processing of pre-ALA synthase. The results in Fig. 4 could be accounted for if: (a) haemin blocked the processing of pre-ALA synthase and led to its rapid degradation; $(b)$ haemin blocked the processing of pre-ALA synthase and inhibited the synthesis of the protein at the translational level; or (c) a combination of the above two possibilities occurred.

\section{Turnover rates of ALA synthase and its precursor}

To estimate the turnover rates of ALA synthase and of its precursor, primary cultures of hepatocytes (pre-treated with AIA) were pulse-labelled with $\left.{ }^{[35} \mathrm{S}\right]$ methionine for $45 \mathrm{~min}$ in the presence and in the absence of haemin, and then a chase with excess 


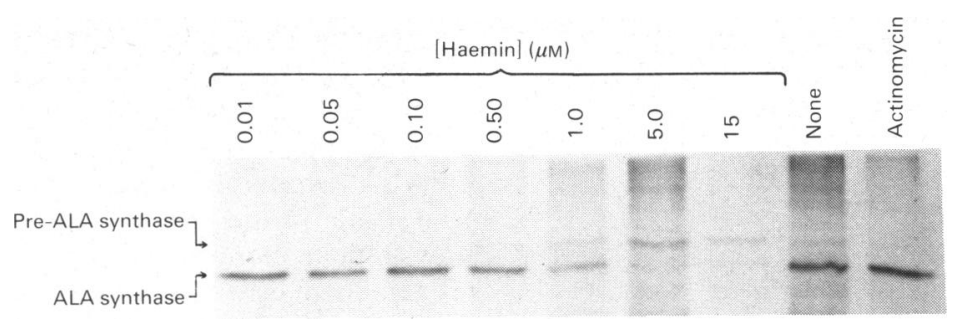

Fig. 4. Effects of various concentrations of haemin and of actinomycin D on the synthesis of ALA synthase as determined by pulse-labelling

Primary cultures of hepatocytes were treated with AIA for $5.5 \mathrm{~h}$, and then the medium was replaced with an identical medium containing AIA but lacking methionine. At that point, haemin (to the final concentration indicated on the Figure) or actinomycin D $(10 \mu \mathrm{g} / \mathrm{ml})$ was added to the medium of the indicated cultures, and then $\left[{ }^{35} \mathrm{~S}\right] \mathrm{methionine}$ $(15 \mu \mathrm{Ci} / \mathrm{ml})$ was added to all cultures immediately. The cells were incubated for $45 \mathrm{~min}$, harvested and then lysed; cells in three 35-mm culture dishes were pooled for each condition. ALA synthase was immune-precipitated from equal volumes of the cell lysates. Equal portions from the immune-precipitates were analysed by gel electrophoresis in the presence of SDS, and labelled proteins on the gel were detected by fluorography. The slots on the fluorograph containing immune-precipitates are shown in the Figure.

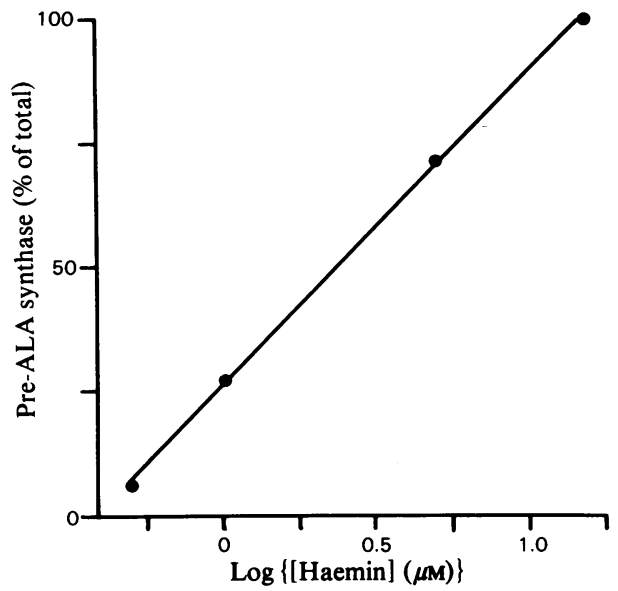

Fig. 5. Effect of haemin concentration on the processing of pre-ALA synthase

Slots on the fluorograph in Fig. 4 were scanned at $546 \mathrm{~nm}$ using a densitometer. For each scan corresponding to a given slot, the area under the peak of pre-ALA synthase was divided by the sum of the areas under the peaks of pre-ALA synthase and mature ALA synthase; this ratio was taken to represent the fraction of pre-ALA synthase that had not been processed during pulse-labelling in the presence of a specific concentration of haemin. The Figure represents the relationship between the fraction of pre-ALA synthase that had not been processed and the concentration of haemin $(0.5 \mu \mathrm{M}$ to $15 \mu \mathrm{M}$ ) in the culture medium of the hepatocytes.

L-methionine was carried out for $45 \mathrm{~min}$ in the presence and in the absence of haemin. After incubation, ALA synthase was immune-precipitated, and the precipitated material was analysed. In cells pulse-labelled for $45 \mathrm{~min}$, mature ALA synthase and a relatively smaller amount of pre-ALA synthase could be detected (Fig. 6, a). After a $45 \mathrm{~min}$ chase, only mature ALA-synthase could be recovered from the cells (Fig. 6, $b$ ). The sum of the areas under the peaks of pre-ALA synthase and of mature ALA synthase after the pulse was compared with the areas under the peak of mature ALA synthase after the chase. The result indicated that mature ALA synthase turned-over with a half time of $120 \mathrm{~min}$ (average of two determinations). This is in good agreement with the results in Fig. 3 discussed above. To determine the fate of pre-ALA synthase after blocking of its processing, cells were pulse-labelled in the presence of haemin to cause the accumulation of radiolabelled pre-ALA synthase (Fig. 6, $c$ ); a chase was then carried out in the presence and in the absence of haemin. From the results after a $45 \mathrm{~min}$ chase in the presence of haemin (Fig. 6, d), it was estimated that pre-ALA synthase turned-over in the presence of haemin with a half time of $30 \mathrm{~min}$ (average of two determinations); the results after a chase in the absence of haemin (Fig. 6,e) indicated that pre-ALA synthase was not processed and that it turned over with a half time of $33 \mathrm{~min}$ (average of two determinations).

The results in Fig. 6 thus indicated that inhibition of processing of pre-ALA synthase by haemin was not reversible and that, in the presence of haemin, pre-ALA synthase turned-over at a rate relatively more rapid than the rate observed for the mature enzyme. The irreversible effect of haemin on the processing of pre-ALA synthase may have been due to the possibility that once in hepatocytes, haemin could not be readily removed from the cells by a change of medium. The values for the turnover rates of ALA synthase and of pre-ALA synthase in the 


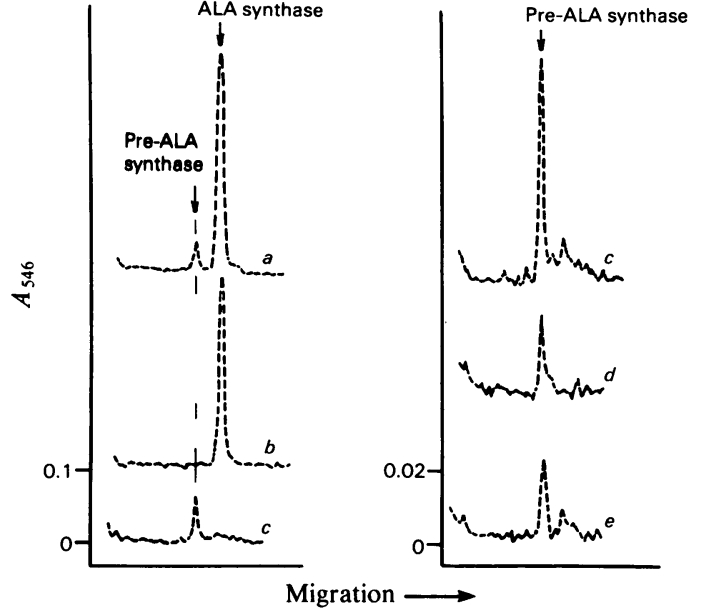

Fig. 6. Recovery of ALA synthase from hepatocytes after a pulse-chase with $\left[{ }^{35} S\right]$ methionine in the presence and in the absence of haemin

Primary cultures of hepatocytes were prepared and incubated with AIA for $5 \mathrm{~h}$. At the end of the incubation, the medium was replaced with an identical medium lacking methionine. At that point, $\left[{ }^{35} \mathrm{~S}\right]$ methionine was added to the culture medium to a specific radioactivity of $15 \mu \mathrm{Ci} / \mathrm{ml}$ to initiate the pulse-labelling. At the end of $45 \mathrm{~min}$, the medium was removed, and, where indicated, fresh medium containing $1.0 \mathrm{ml}$ of $\mathrm{L}$-methionine $/ \mathrm{ml}$ was added to some of the cultures to initiate a $45 \mathrm{~min}$ chase. AIA was present in the medium throughout these procedures. Haemin was added to the culture medium where indicated, to a final concentration of $15 \mu \mathrm{M}$. At the end of the incubation, the cells (three 35-mm culture dishes for each condition) were harvested and then lysed. ALA synthase was immune-precipitated from portions of each lysate containing 750000 c.p.m. of ${ }^{35} \mathrm{~S}$ incorporated into trichloroacetic acid-insoluble material. Equal portions from each immune-precipitate were then analysed by polyacrylamide-gel electrophoresis, and radiolabelled proteins were detected by fluorography. Slots on the resulting fluorograph were scanned with a densitometer at the two indicated sensitivities, and the scans of the given slots are shown in the Figure. The conditions were: $a$, pulse only; $b$, pulse and chase; $c$, pulse in the presence of haemin; $d$, pulse and chase, both in the presence of haemin; $e$, pulse in the presence of haemin and then chase in the absence of haemin.

presence of haemin (half times of $120 \mathrm{~min}$ and $30 \mathrm{~min}$ respectively) were used to correct the results in Fig. 5; after the correction, we determined that the concentration of haemin required to inhibit the processing of pre-ALA synthase by $50 \%$ was actually $1.6 \mu \mathrm{M}$.

\section{Discussion}

The activity of ALA synthase in hepatocytes appears to be regulated by free intracellular haem (Welch \& Badawy, 1980; Yamamoto et al., 1981). The results of studies on animals exposed to porphyrogenic agents that induce liver ALA synthase indicated that haemin blocked the increase in the enzyme's activity as rapidly as cycloheximide and more rapidly than actinomycin D (Sassa \& Granick, 1970; Tyrrell \& Marks, 1972; Strand et al., 1972). The results of our determinations in Fig. 3 on the activity of ALA synthase confirmed these findings. In addition, our measurements on ALA synthase by immune-blotting indicated that the drop in the activity of ALA synthase in cells maintained in the presence of haemin could be accounted for by a decrease in the amount of the enzyme in the hepatocytes; thus haemin did not appear to affect the enzyme's activity by acting as an inhibitor. Our results thus agree with those of Wolfson et al. (1979), who reported that ALA synthase activity in isolated mitochondria remained unchanged under conditions where endogenous haem synthesis was stimulated 75 times the normal rate through variations in the concentration of the substrate of ferrochelatase.

The results of our pulse-chase studies indicated that an immediate effect of haemin was the inhibition of maturation of pre-ALA synthase, which led to the turnover of this protein. Our results also indicated that a haemin concentration of $2 \mu \mathrm{M}$ in the culture medium inhibited the processing of pre-ALA synthase by $50 \%$. Since most mitochondrial proteins are synthesized in the cytoplasm as precursors and become processed immediately after their translocations into mitochondria (Ades, 1982), it is likely that haemin blocked the transfer of pre-ALA synthase from the cytoplasm into mitochondria; we have no data to test this hypothesis at this time, however. Along these lines, Kikuchi and his colleagues (reviewed by Kikuchi \& Hayashi, 1981) reported that haemin injections into AIA-treated animals caused the accumulation of ALA synthase activity in the cytosol fractions of livers from haemin-treated animals. These investigators established also through pulse-labelling analyses that the accumulation of ALA synthase activity in the cytosol of rat liver was the result of the presence of newly-synthesized ALA synthase in that fraction (Yamauchi et al., 1980). It was not possible to determine from the results of their studies, however, whether the activity of ALA synthase detected in the cytosol fractions was in fact due to the accumulation of the precursor of ALA synthase or to newlysynthetized ALA synthase that had selectively leaked out of mitochondria during tissue homogenization. Thus the possibility that haemin blocks 
the maturation of pre-ALA synthase by inhibiting the transfer of this protein into mitochondria remains to be rigorously tested.

This work was supported by grants GM 27878 and GM 31672 from the National Institutes of Health.

\section{References}

Ades, I. Z. (1982) Mol. Cell. Biochem. 43, 113-127

Ades, I. Z. (1983) Biochem. Biophys. Res. Commun. 110, 42-47

Ades, I. Z. \& Harpe, K. G. (1981) J. Biol. Chem. 256, 9329-9333

Ades, I. Z. \& Harpe, K. G. (1982) Biochem. J. 205, 257-263

Bonner, W. M. \& Laskey, R. A. (1974) Eur. J. Biochem. 46, 83-88

Borthwick, I. A., Srivastava, G., Brooker, J. D., May, B. K. \& Elliot, W. H. (1983) Eur. J. Biochem. 129, $615-620$

Granick, S. \& Sassa, S. (1971) Metabolic Pathways, pp. 77-141, Academic Press, New York

Ham, R. G. (1965) Proc. Natl. Acad. Sci. U.S.A. 53, 288-293

Kikuchi, G. \& Hayashi, N. (1981) Mol. Cell. Biochem. 37, 27-41

Laemmli, U. K. (1970) Nature (London) 227, 680-685

Lowry, O. H., Rosebrough, N. J., Farr, A. L. \& Randall, R. J. (1951) J. Biol. Chem. 193, 265-275
Paterniti, J. R., Jr. \& Beattie, D. S. (1979) J. Biol. Chem. 254, 6112-6118

Patton, G. M. \& Beattie, D. S. (1973) J. Biol. Chem. 248, 4467-4474

Sassa, S. \& Granick, S. (1970) Proc. Natl. Acad. Sci. U.S.A. 67, 517-522

Sassa, S., Kappas, A., Berstein, S. \& Alvares, A. P. (1979) J. Biol. Chem. 254, 729-735

Scotto, A. W., Chang, L.-F. L. \& Beattie, D. S. (1983) J. Biol. Chem. 258, 81-90

Srivastava, G., Borthwick, I. A., Brooker, J. D., May, B. K. \& Elliot, W. H. (1982) Biochem. Biophys. Res. Commun. 109, 305-312

Srivastava, G., Borthwick, I. A., Brooker, J. D., May, B. K. \& Elliot, W. H. (1983) Biochem. Biophys. Res. Commun. 110, 23-31

Strand, L. J., Manning, J. \& Marver, H. S. (1972) J. Biol. Chem. 247, 2820-2827

Tyrrell. D. L. J. \& Marks, G. S. (1972) Biochem. Pharmacol. 21, 2077-2093

Welch, A. N. \& Badawy, A. A. B. (1980) Biochem. J. 192, 403-410

Wolfson, S. J., Bartczak, A. \& Bloomer, J. R. (1979) J. Biol. Chem. 254, 3543-3546

Yamamoto, M., Hayashi, N. \& Kikuchi, G. (1981) Arch. Biochem. Biophys. 209, 451-459

Yamamoto, M., Hayashi, N. \& Kikuchi, G. (1982) Biochem. Biophys. Res. Commun. 105, 985-990

Yamauchi, K., Hayashi, N. \& Kikuchi, G. (1980) J. Biol. Chem. 255, 1746-1751 